\title{
Planejamento e Controle Orçamentário em Empresas Concessionárias de Rodovias: Uma Pesquisa Empírica
}

\author{
Planning and Budget Control in Highway Utility Companies: An Empirical Research
}

\section{Fábio de Azevedo Pereira}

Especialista em Controladoria na Universidade Federal do Paraná

Professor do Departamento de Administração das Faculdades Integradas do Vale do Ribeira

Endereço: Rua Eric Verhulst, n ${ }^{\circ} 569$, Nova Registro

CEP: 11900-000 - Registro/SP - Brasil

E-mail: p_fabioazevedo@hotmail.com

Telefone: (13) 3822-4760

\section{Márcia Maria dos Santos Bortolocci Espejo}

Doutora em Controladoria e Contabilidade na Universidade de São Paulo

Professora e Coordenadora do Mestrado em Contabilidade da Universidade Federal do Paraná Endereço: Av. Pref. Lothário Meissner, nº 632, Jardim Botânico

CEP: 80210-170 - Curitiba/PR - Brasil

E-mail: marciabortolocci@gmail.com

Telefone: (41) 3360-4193

Artigo recebido em 20/10/2010. Revisado por pares em 24/05/2012. Reformulado em 30/05/2012. Recomendado para publicação em 20/06/2012 por Sandra Rolim Ensslin (Editora Científica). Publicado em 28/06/2012. 


\title{
Resumo
}

O objetivo da presente pesquisa é identificar as características da gestão orçamentária das empresas do ramo de concessão rodoviária do Brasil. Trata-se de uma pesquisa descritiva, realizada nas empresas cadastradas na Associação Brasileira de Concessionária de Rodovias. Como resultado, constatou-se que $73 \%$ das concessionárias utilizam como principal metodologia o orçamento por atividades que é uma extensão do Custeio Baseado em Atividades (ABC). Tal fato justifica-se, pois nesse ramo as empresas realizam diferentes e complexas obras de infraestrutura e a mensuração das atividades torna-se essencial para o controle de recursos e o cumprimento das metas estabelecidas para o desenvolvimento dessas obras.

Palavras-chave: Gestão orçamentária. Métodos de orçamento. Concessão de serviços públicos de rodovias.

\begin{abstract}
The objective of this research is to identify the characteristics of budgetary enterprises of the branch road concession in Brazil. This is a descriptive study, conducted among the companies registered with the Brazilian Association of Highway Concessionaire. As a result it was found that $73 \%$ of dealers as the main methodology used for activities that the budget is an extension of Activity-based Costing (ABC). This fact is justified, because in this business firms undertake different and complex infrastructure projects and measurement activities is essential for the control of resources and meet the goals established for the development of these works.
\end{abstract}

Keywords: Budgeting management. Budgeting methods. Allocation of public highways.

\section{Introdução}

O ramo de concessões é um dos mais promissores atualmente no Brasil, tendo em vista a crescente tendência de transferência dos direitos e responsabilidades do Estado para empresas privadas, inerentes a alguns tipos de serviços que antes só eram pertinentes ao governo. Esta situação vem ocorrendo há algum tempo, mas, na última década, está se tornando uma tendência nacional principalmente no setor rodoviário.

O atual cenário econômico mundial tem incentivado grandes investimentos em países emergentes, já que as grandes corporações dos países desenvolvidos procuram novos mercados a serem explorados e desenvolvidos para compensar a estagnação do mercado em seus países. Além disso, existem mais dois fatos relevantes a serem considerados que acontecerão no Brasil na próxima década: a Copa do Mundo de 2014 e as Olimpíadas de 2016, eventos que exigirão grande quantidade de investimentos, principalmente em infraestruturas rodoviária, metroviária, ferroviária e aeroviária, ocasionando, com isso, expectativas reais de crescimento para o ramo de concessões no País.

Essa tendência de expansão no setor de concessões revela as novas oportunidades e 
expectativas positivas nos próximos anos; porém surgirão adicionalmente grandes desafios a serem vencidos devido à rotineira necessidade de adaptações decorrentes das constantes mudanças nos processos internos de gestão de recursos em cada organização e dos voláteis fatores externos que afetam o negócio.

Com esses argumentos e tendo em vista que as concessionárias de rodovias desempenham e irão desempenhar cada vez mais papel fundamental para o desenvolvimento econômico e social do País e que os procedimentos relacionados à gestão orçamentária são de suma importância para a eficiência e eficácia organizacional, chega-se então à questão de pesquisa que orienta a presente investigação: Quais as características da gestão orçamentária apresentadas por empresas do ramo de concessão rodoviária do Brasil?

Nesse sentido, o objetivo da pesquisa é identificar as características da gestão orçamentária de empresas do ramo de concessão rodoviária do Brasil, por meio da aplicação de questionários com informações específicas e gerais aos gestores orçamentários das empresas, da análise dos dados obtidos e verificação dos conceitos e metodologias utilizadas no processo de gestão orçamentária e também da identificação dos principais métodos de gestão orçamentária utilizados pelas organizações do ramo.

Esta pesquisa do tipo levantamento sobre gestão orçamentária em empresas concessionárias de rodovia apresenta grande relevância para o ramo de concessões, pois, além de contribuir com a massa teórica sobre o tema, seus resultados poderão cooperar para melhorias na gestão das organizações, envolvendo planejamento e controle orçamentários.

O presente estudo está estruturado em seis seções, incluindo-se esta introdução. A seção 2 elucida abordagens teórico-empíricas sobre os conceitos e objetivos do orçamento e as principais metodologias relacionadas ao instrumento gerencial em análise, apresentam-se estudos atuais e similares ao tema, bem como apresentam-se conceitos e características de uma concessão rodoviária. A terceira seção contém a metodologia aplicada à pesquisa; já na seção 4 é exposta a apresentação e a análise dos dados. Por fim, na quinta seção, são apresentadas as considerações finais e as recomendações da pesquisa.

\section{Referencial Teórico}

A visualização dos conceitos, objetivos e características do orçamento são essenciais para o desenvolvimento da presente investigação, pois a partir dessa contextualização, podemse especificar as peculiaridades das principais metodologias utilizadas no cenário atual.

Além dos conceitos literários clássicos, essenciais ao bom desenvolvimento de uma pesquisa acadêmica, buscou-se elucidar alguns estudos atuais e similares ao tema então abordado, com a finalidade de possibilitar uma estruturada comparação entre os processos orçamentários nas organizações, ainda que em circunstâncias diversificadas.

\subsection{Conceitos, Objetivos e Características do Orçamento}

Dentre as muitas práticas adotadas no controle de gestão, o controle orçamentário tem sido amplamente discutido na literatura (HANSEN et al., 2003; SILVA, GONÇALVES, 2006; SILVA, GONÇALVES, 2008).

Segundo Horngren (2000, p. 125), orçamento é a "expressão quantitativa de um plano de ação futuro da organização para um determinado período". De acordo com Brookson 
(2000), orçamento é um plano de atividades futuras que pode assumir diversas formas, porém normalmente reflete os departamentos e o conjunto da empresa em termos financeiros, fornecendo a base para se medir o desempenho da organização, ou seja, é uma declaração de planos financeiros e não financeiros para um período que ainda virá.

Para que as funções do orçamento sejam mais bem desempenhadas, deve-se associálas às funções administrativas, abrangendo o planejamento, execução, controle, avaliação, motivação e coordenação (WELSCH, 1973 apud LUNKES, 2003). A eficiência no desempenho e acompanhamento das atividades realizadas nas organizações é extremamente relevante para que estas possam ser bem sucedidas. Portanto, são cada vez mais necessários o planejamento, a organização e o controle dos acontecimentos que envolvem recursos destinados aos diversos setores da empresa. Diante dessas considerações, é interessante ressaltar que o fator fundamental para que a empresa tenha um bom desempenho é a responsabilidade que a administração tem em realizar um planejamento adequado para conseguir que as pessoas que compõem a organização desempenhem atividades condizentes com os objetivos dos gestores (ESPEJO, 2008).

Conforme Frezatti (2006, p. 44), o orçamento é "um dos pilares da gestão e uma das ferramentas fundamentais para que o accountability, a obrigação dos gestores de prestar contas de suas atividades, possa ser encontrado". Logo, o orçamento oferece sustentabilidade às organizações diante da competitividade, da abertura de mercados e da necessidade constante de adaptação aos fatores mercadológicos.

De acordo com Jones e Trentin (1978, p. 1), "o papel de um bom orçamento na direção de uma empresa é melhor compreendido quando relacionado aos fundamentos administrativos". Os mesmos autores citam também que, dentre os variados conceitos e metodologias de gestão empresarial, podem-se resumir três funções básicas: planejamento, execução e controle, e que são estes os elementos-chave de um processo administrativo.

Brookson (2000) ordena de forma diferente os objetivos do orçamento, quando afirma que os tais instrumentos são essenciais para o planejamento e o controle da empresa. Eles ajudam a coordenar as ações dos líderes de diferentes áreas, estabelecem um compromisso com os objetivos da empresa, conferem autoridade ao gestor de cada área para alocar despesas e fornecer metas claras de receita.

O mesmo autor ainda cita que os seis objetivos principais do orçamento são: planejamento, coordenação, comunicação, motivação, controle e avaliação, sendo que cada um desempenha uma função essencial no processo de gestão orçamentária, conforme exposto no Quadro 1.

Quadro 1 - Os seis objetivos principais do orçamento

\begin{tabular}{|l|l|}
\hline OBJETIVOS & \multicolumn{1}{|c|}{ DESCRIÇÃO } \\
\hline PLANEJAMENTO & $\begin{array}{l}\text { Auxiliar a programar atividades de um modo lógico e sistemático que corresponda à } \\
\text { estratégia de longo prazo da empresa. }\end{array}$ \\
\hline COORDENAÇÃO & $\begin{array}{l}\text { Ajudar a coordenar as atividades de diversas partes da organização e garantir a } \\
\text { consistência dessas ações. }\end{array}$ \\
\hline COMUNICAÇÃO & $\begin{array}{l}\text { Informar mais facilmente os objetivos, oportunidades e planos da empresa aos } \\
\text { diversos gerentes de equipes. }\end{array}$ \\
\hline MOTIVAÇÃO & $\begin{array}{l}\text { Fornecer estímulo aos diversos gerentes para que atinjam metas pessoais e da } \\
\text { empresa. }\end{array}$ \\
\hline
\end{tabular}


Planejamento e Controle Orçamentário em Empresas Concessionárias de Rodovias: Uma Pesquisa Empírica

\begin{tabular}{|l|l|}
\hline CONTROLE & $\begin{array}{l}\text { Controlar as atividades da empresa por comparação com os planos originais, } \\
\text { fazendo ajustes, onde necessário. }\end{array}$ \\
\hline AVALIAÇÃO & $\begin{array}{l}\text { Fornecer bases para a avaliação de cada gerente, tendo em vista duas metas pessoais } \\
\text { e as de seu departamento. }\end{array}$ \\
\hline
\end{tabular}

Fonte: Brookson (2000, p. 9).

\subsection{Principais metodologias orçamentárias}

Com o passar dos anos, o orçamento foi se adaptando e acompanhando as tendências modernas das novas teorias de gestão. Contudo ainda é foco de diversas críticas por parte de gestores e estudiosos, que colocam em xeque a utilidade e eficiência dessa ferramenta e se a sua utilização é vantajosa para as organizações (HOPE e FRASER, 2003). Nesse contexto, Fank, Angonese e Lavarda (2011) realizaram uma pesquisa com o objetivo de verificar se as críticas feitas ao orçamento empresarial são reconhecidas pelos coordenadores dos cursos de pós-graduação de uma instituição de ensino superior. Os resultados evidenciaram que a maioria das críticas feitas ao orçamento não foram reconhecidas, com exceção às criticas que mencionam que o orçamento tem como foco a redução de custos e não a criação de valor, que a revisão do orçamento é lenta e que a instituição não o gerencia de forma rápida.

Diversos métodos foram desenvolvidos no sentido de aprimorar a gestão orçamentária. A Figura 1 contempla a evolução das metodologias relacionadas ao orçamento, que serão detalhadas a seguir.

Figura 1 - Do orçamento empresarial ao orçamento perpétuo

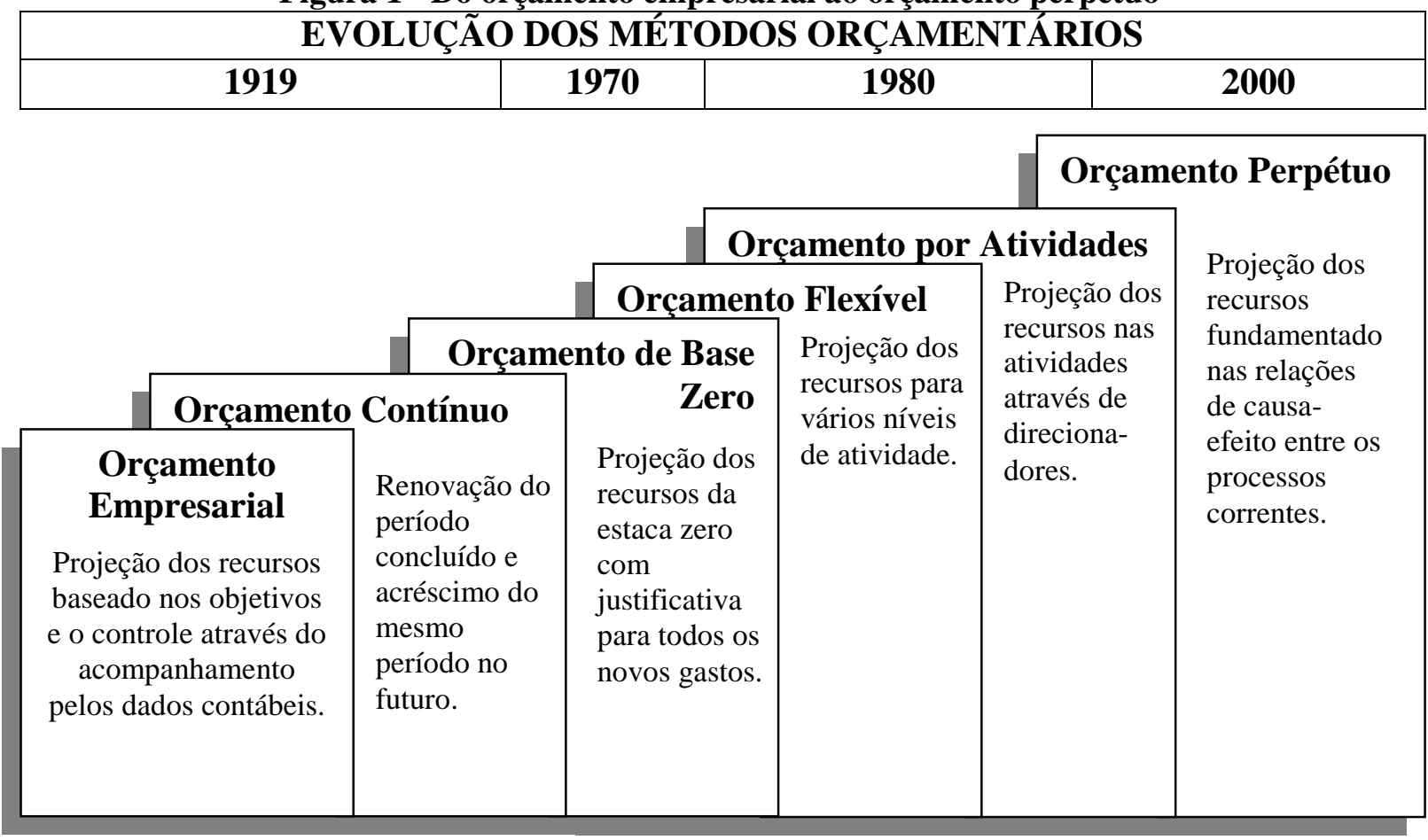

Fonte: Lunkes (2003, p.38).

125 ISSN 2175-8069, UFSC, Florianópolis, v.9, n.17, p. 121-142, jan./jun., 2012 


\subsubsection{Orçamento Contínuo}

Esse método tem como foco a revisão contínua, subtraindo-se dados do mês anterior e acrescentando-se dados orçados para o mesmo mês do próximo ano. A utilização dessa metodologia orçamentária vem se tornando cada vez mais frequente hoje em dia nas empresas (WELSCH, 1983).

O orçamento contínuo é baseado em um prazo movente que se estende em função de um prazo fixo. Quando um período termina, outro é acrescentado ao final do ciclo. Geralmente ele é elaborado em 12 meses, ou seja, quando o mês atual termina, outro é acrescentado no futuro. Também é frequentemente usado quando se acredita que planos realistas somente podem ser feitos para curtos períodos, e é desejável ou necessário replanejar e refazer projeções continuamente por forças das circunstâncias (WELSCH, 1983).

De acordo com Vaena e Huetz (1961), o orçamento contínuo, também chamado de dinâmico, é aquele que acompanha as mutações e os desenvolvimentos que se verificam durante um exercício orçamentário e é elaborado e aprovado no início do exercício, passando a sofrer reajustes periódicos, motivados por novos processos produtivos, novos produtos introduzidos e não previstos nos planos traçados, alterações nos níveis de preços dos itens orçados, entre outros fatores. As alterações que por açaso venham a ser feitas deverão ser aprovadas pela alta administração e em seguida transcritas com comunicação especial nos orçamentos de cada departamento.

\subsubsection{Orçamento Base Zero (OBZ)}

O OBZ consiste em uma técnica operacional de planejamento construída sem levar em consideração as receitas e despesas realizadas no passado (COSTA, MORITZ, MACHADO, 2007). A projeção dos dados é realizada como se as operações estivessem começando do zero, assim como a necessidade de justificar os gastos, sem uso dos dados históricos. Nessa metodologia, os gestores estimam e justificam os valores orçados como se a empresa estivesse iniciando suas operações. De acordo com Ferreira (1985), o Orçamento Base Zero surgiu nos Estados Unidos em 1960 inicialmente nas organizações públicas.

Um dos objetivos desse modelo orçamentário é apresentar-se como alternativa para solucionar um problema proporcionado pelos modelos que levam em consideração os orçamentos atuais e as informações de execução de orçamentos passados. No OBZ, o ano anterior não é utilizado como base para elaboração do atual. Essa metodologia necessita que todas as atividades estejam justificadas e priorizadas antes das decisões relativas à quantia de recursos a serem alocadas em cada departamento ou as atividades serem tomadas. $\mathrm{O}$ Orçamento Base Zero não aceita o conceito tradicional do orçamento e principalmente a ideia do orçamento incremental que leva em consideração os dados do ano anterior mais um adicional.

Seguindo esse pensamento, nota-se que cada atividade da empresa será rediscutida, não em função de valores maiores ou menores, e sim na razão ou não da sua existência. Após a definição da existência da atividade, será feito um estudo, partindo do zero, de quanto deveria ser o gasto para a manutenção e a estruturação daquela atividade, e quais seriam suas metas e objetivos (LUNKES, 2003). Sendo assim, pode-se dizer que o Orçamento Base Zero está fortemente ligado ao conceito de custo-padrão ideal. 
Segundo Costa, Moritz e Machado (2007), o OBZ proporciona vantagens, pois possibilita maior controle dos gastos pelas instituições e também melhor acompanhamento e conhecimento das atividades que originam essas despesas, garantindo assim informações mais confiáveis para a elaboração do planejamento da organização.

\subsubsection{Orçamento Flexível}

Segundo Horngren (1985), o orçamento flexível é elaborado para uma faixa de níveis, e não para apenas um nível de atividade, sendo basicamente um conjunto de orçamentos que podem ser ajustados a qualquer nível de atividade. Trata-se de orçamento por cenários em conformidade com oscilações das variáveis que constituem as premissas do processo orçamentário.

Padoveze (2009, p. 202) cita um aspecto relevante ao elaborar o orçamento flexível, o da importância em “... não assumir nenhuma faixa de quantidades ou nível de atividade esperado. É feito apenas o orçamento dos dados unitários, e as quantidades a serem assumidas seriam as que realmente acontecem".

\subsubsection{Orçamento por Atividades (ABB)}

Já no início da década de 1980, surge o Orçamento por Atividades como uma extensão do Custeio Baseado em Atividades ( $A B C$-Activity Based Costing), tendo como foco a projeção dos recursos de acordo com as atividades e o uso de direcionadores para estimar e controlar os resultados. Esse modelo orçamentário usa a informação sobre os direcionadores no planejamento e no processo de avaliação. Para Cokins (apud Lunkes, 2003) o custeio baseado em atividades tem três funções básicas: ampliar o entendimento sobre os custos, dar apoio à tomada de decisão e ajudar no planejamento preditivo.

O progresso que houve do $\mathrm{ABC}$ para o Orçamento por Atividades é natural, já que o foco é usar o $\mathrm{ABC}$ para estimar os custos e necessidades de recursos por meio de direcionadores. Nota-se então a relevância de estudar o ABC para se chegar a um entendimento mais eficiente sobre as características do orçamento por atividades. Segundo Horngren et al. (2000, p. 703), o custeio baseado em atividades "é um método de custeio voltado para as atividades como objeto fundamental de custos. Emprega o custo dessas atividades como base de apropriação de custos a outros objetos de custo, como produtos, serviços, clientes etc.".

Segue na Figura 2 o esquema básico de alocação de recursos no ABC, apresentando as facilidades e dificuldades de identificação e alocação dos custos diretos, indiretos e dos outros custos indiretos que possam existir. Esta figura elucida a concepção conceitual do ABC para alocar os custos aos objetos de custeio.

Figura 2 - Esquema básico de alocação de recursos no ABC

\begin{tabular}{|c|c|c|}
\hline \multicolumn{3}{|c|}{ Recursos } \\
\hline Custos Diretos & Custos Indiretos & Outros Custos Indiretos \\
\hline $\begin{array}{l}\text { Fácil identificação com o objeto de } \\
\text { custeio }\end{array}$ & $\begin{array}{c}\text { Relativa dificuldade de } \\
\text { identificação com o objeto de }\end{array}$ & $\begin{array}{l}\text { Alto grau de dificuldade de } \\
\text { identificação com o objeto de }\end{array}$ \\
\hline
\end{tabular}

127 ISSN 2175-8069, UFSC, Florianópolis, v.9, n.17, p. 121-142, jan./jun., 2012 
Fábio de Azevedo Pereira e Márcia Maria dos Santos Bortolocci Espejo

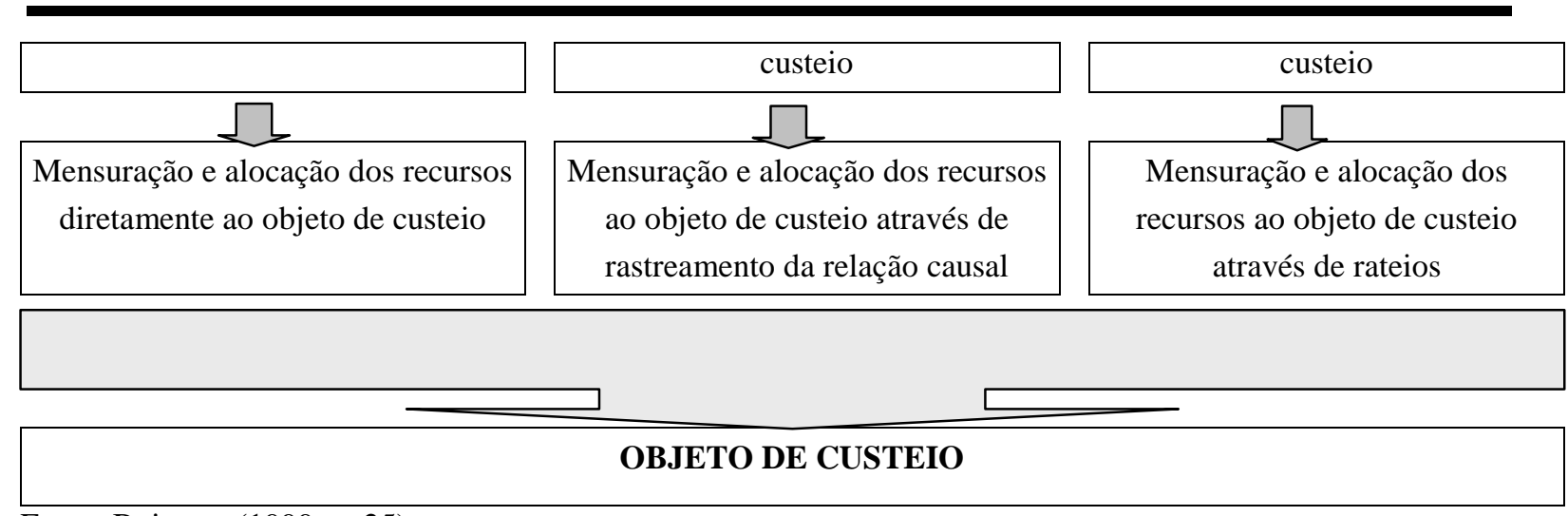

Fonte: Boinvert (1999, p. 25).

Já a Figura 3 expressa o caminho dos recursos, utilizando direcionadores para a alocação dos recursos às atividades e destas aos objetos de custeio.

Figura 3 - Esquema básico de alocação de recursos e atividades

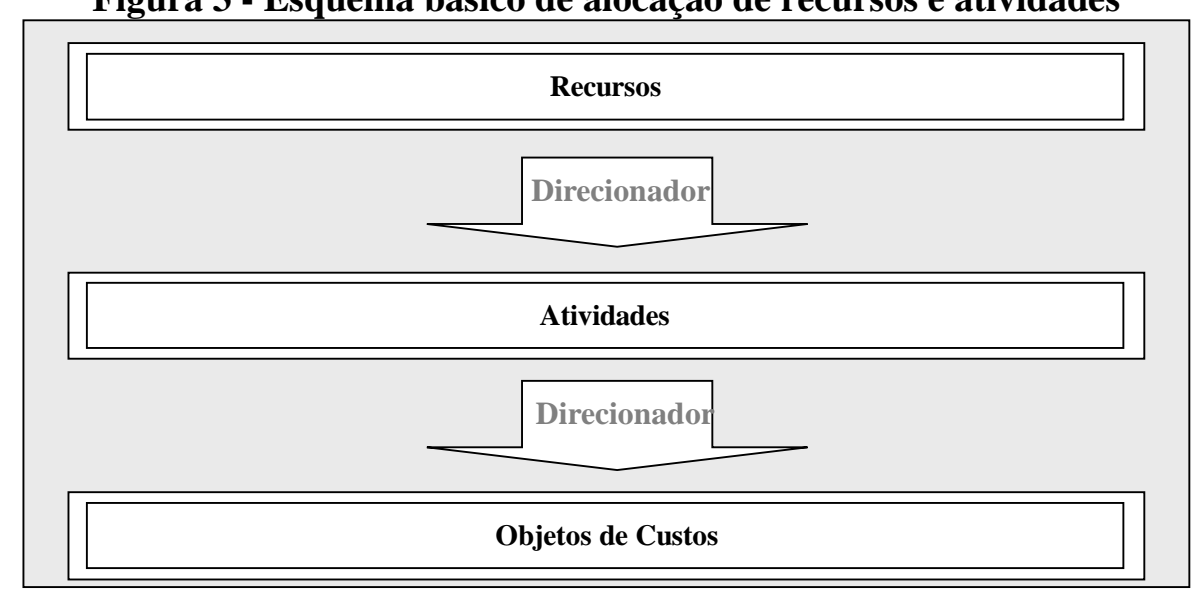

Fonte: Boisvert (1999 p. 25).

\subsubsection{Orçamento Perpétuo}

Esta metodologia prevê o uso dos recursos fundamentado na relação causa-efeito entre os processos correntes (BRIMSON, 1996), em que seus atributos-chave são, entre outros, atualizar os planos quando ocorrem eventos-chave, modelar relatórios de dados de numerosas fontes e usar dados atualizados para validar os processos. Esse tipo de orçamento permite clara identificação das inter-relações entre as atividades da empresa e como essas relações influenciam no desempenho individual e no resultado global.

Por suma, torna-se relevante ressaltar que o Orçamento Perpétuo permite a identificação e a previsão dos recursos por meio da relação causa-efeito e que uma das grandes vantagens desse método é a possibilidade de estimar recursos de acordo com os objetivos e as políticas da empresa, sendo que a gestão do processo possibilita aos responsáveis focalizar a atenção na definição de estratégias, redirecionando recursos quando a estratégia não está sendo consumada. 


\subsection{Estudos Similares acerca da Gestão Orçamentária}

Nesta subseção, serão abordados alguns artigos científicos publicados em revistas e periódicos em caráter permanente, com a finalidade de maximizar o entendimento organizacional sobre do objeto de pesquisa, agregando assim, subsídios para estruturar possíveis comparações circunstanciadas conforme cada abordagem realizada.

De acordo com pesquisa realizada por Silva e Gonçalves (2008), que buscou caracterizar a utilização do sistema orçamentário, por meio de um estudo multicaso realizado em duas empresas brasileiras de grande porte, onde o quadro referencial teórico baseou-se na abordagem contingencial e estudos sobre cinco itens: tecnologia, participação, acompanhamento orçamentário, integração do sistema orçamentário e ênfase na utilização; suplementados por mais cinco itens que apresentaram o contexto corporativo: tamanho, diversificação, descentralização, dinamismo, posição e participação no mercado. Verificou-se então, que ambas as empresas pesquisadas utilizavam o sistema orçamentário como principal mecanismo de controle gerencial e que não havia participação da média e baixa gerência no processo de planejamento estratégico e em uma delas, não havia sequer divulgação do planejamento estratégico para a média gerência. Percebeu-se também, a luz dos estudos realizados, que a empresa $\mathrm{A}$, com maior uso do sistema orçamentário, possibilitava mais participação dos colaboradores e procurava implantação de medidas corretivas a partir da utilização das informações deste sistema.

Um estudo realizado por Fank; Angonese e Lavarda (2011) elucidou, que o orçamento é uma das ferramentas de gestão que mais recebe críticas por parte dos pesquisadores nos últimos anos, porém, ainda é uma das mais citadas no meio acadêmico em nível de importância para auxiliar as funções administrativas de planejamento e controle, nesse sentido, procurou-se verificar se as críticas realizadas ao orçamento empresarial são reconhecidas pelos gestores dos cursos de pós-graduação em uma instituição de ensino superior. Logo, os resultados mostraram que, entre os respondentes, as críticas em sua maioria não foram reconhecidas, com exceção às que mencionam que o orçamento tem foco na redução de custo e não na criação de valor, que a revisão do orçamento é lenta e a instituição não o gerencia de forma rápida. De modo geral, a maior parte dos respondentes posicionou-se discordando ou discordando parcialmente das críticas analisadas.

Segundo Costa; Moritz e Machado (2007) em estudo realizado com o objetivo de identificar as contribuições do Orçamento Base Zero (OBZ) para o desenvolvimento do planejamento e do controle de resultados em organizações empresariais como foco nos reflexos na gestão de empresas, verificou-se que o OBZ não é unicamente uma ferramenta para reduzir custos e melhorar as economias, e sim uma ferramenta de gestão que mira proporcionar o desenvolvimento de práticas mais eficientes para a elaboração de suas atividades, assim como para a otimização de recursos financeiros.

Panucci Filho et al., (2010), primeiramente discute o papel do orçamento nas organizações ao abordar problemas costumeiramente existentes no ambiente de gestão e depois investiga o desenvolvimento e utilização do orçamento numa amostra piloto de 28 indústrias de confecções da Região de Maringá/PR, buscando, com isso, investigar se os problemas atribuídos ao orçamento ainda persistem nas organizações, e se o seu uso atende as perspectivas dos gestores para tomada de decisões. Verificou-se então que junto ao nível de adoção do orçamento pelos gestores investigados: maior parte deles conhece, mas não 
utilizam. Em conclusão ao estudo referido notou-se que a adoção do orçamento empresarial e suas variáveis de controle estão evoluindo nas empresas da amostra.

Por fim, em estudo realizado por Verhagem e Lavarda (2011) com o objetivo de identificar em que medida os fatores contingenciais (estratégia ambiente, tecnologia, estrutura e tamanho) influenciaram nas principais inovações do processo orçamentário da empresa investigada, evidenciou-se que os fatores contingenciais do ambiente, a tecnologia e, principalmente, o tamanho influenciaram as inovações nos atributos do sistema orçamentários da organização.

\subsection{Empresas Concessionárias de Rodovia}

$\mathrm{Na}$ recente história social e econômica do Brasil, nota-se uma tendência de transferências de responsabilidades do poder público para a iniciativa privada. Com relação à malha rodoviária do País não é diferente; pelo contrario, esse é o setor em que essa condição mais se desenvolve. As melhorias, recuperações e manutenções das rodovias que antes eram obrigações do Estado, hoje passam a ser interessantes para grandes empresas privadas; estas que, por sua vez, adquirem junto com esse passivo o direito de explorar a malha viária por meio da cobrança de pedágio. Essa situação é regulada por meio de um contrato de concessão e esse tópico objetiva elucidar conceitos e objetivos desse acordo realizado entre administração pública e entidades privadas.

De acordo com Souto (2001; p. 30), “concessão envolve uma atividade fim do estado, que é a prestação de serviços públicos; é um contrato administrativo por meio do qual a administração pública delega a um particular a gestão e a execução, por sua conta e risco sob controle do Estado, de uma atividade definida por lei como serviço público (CF, art. 175)".

A Constituição Federal Brasileira, no caput do seu art. 175, confia ao poder público prestar serviço público diretamente ou sob o regime de concessão sempre por meio de licitação, sendo necessária uma lei para regular e dispor sobre o regime das empresas concessionárias de serviços públicos, o caráter especial de seu contrato e de sua prorrogação, bem como regulações contratuais, fiscalização e rescisão da concessão, ou até mesmo os direitos dos usuários, política tarifária e a obrigação de manter serviço adequado (BRASIL, Congresso Nacional,1988).

A Lei $\mathrm{n}^{\circ}$ 8.987, de 13 de fevereiro de 1995, dispõe que as concessões de serviços públicos e de obras públicas e as permissões de serviços públicos deverão ser regidas pelos termos do art. 175 da Constituição Federal, pelas normas legais pertinentes e pelas cláusulas dos indispensáveis contratos, (BRASIL, Congresso Nacional, 1995). Para melhor entendimento, a Lei $\mathrm{n}^{\circ} 8.987 \mathrm{em}$ seu artigo $2^{\circ}$ inciso II, dispõe que a delegação de sua prestação (serviço público) é feita pelo poder concedente, mediante licitação, na modalidade de concorrência, à pessoa jurídica ou consórcio de empresas que demonstre capacidade para seu desempenho, por sua conta e risco e por prazo determinado (BRASIL, Congresso Nacional, 1995).

De acordo com o mesmo autor (2003), a concessão quando outorgada precisa ser feita sem exclusividade, para que seja possível a competição entre os interessados e assim, favoreça os usuários com melhores serviços e tarifas acessíveis. É importante ressaltar que a concorrência acontece no momento do processo licitatório ou leilão dos lotes e que após o arremate da concessão não existe concorrência ou disputa pelo tráfego entre as empresas. 
Conforme Medauar (1995), a administração não pode se desvincular do serviço público, quando concedido. O serviço é concedido, porém permanece serviço público, ou seja, a concessão não configura abandono, desligamento total. Logo, o Estado continua "fiador" da execução perante a coletividade. De acordo com a Associação Brasileira de Concessionárias de Rodovias - ABCR (2010), o Brasil tem atualmente 50 concessionárias que administram mais de 12,5 mil quilômetros de rodovias em oito estados: Rio Grande do Sul, Santa Catarina, Paraná, São Paulo, Rio de Janeiro, Espírito Santo, Minas Gerais e Bahia.

\section{Metodologia da Pesquisa}

Esta etapa tem como objetivo orientar a direção a ser tomada para o desenvolvimento da pesquisa, definindo-se a metodologia e o tipo de estudo a ser realizado. A metodologia é utilizada com a finalidade de orientar a direção para se produzir ciência. Segundo os ensinamentos de Richardson (2008, p. 22), “[...] são os procedimentos e regras utilizadas por determinado método".

\subsection{Natureza da Pesquisa}

Quanto à natureza da abordagem da investigação a presente pesquisa é de cunho quantitativo, e quanto ao objetivo trata-se de pesquisa descritiva, cujas principais características são observar, registrar, analisar, descrever e correlacionar fatos ou fenômenos sem manipulá-los, procurando descobrir com precisão a frequência em que um fenômeno ocorre e sua relação com outros fatores (CERVO; BERVIAN, 2002). O método descritivo pode assumir diversas formas relacionadas com o enfoque que o pesquisador deseja atribuir a seu estudo, sendo que a presente investigação pode ser classificada como uma pesquisa survey (levantamento), pois visa determinar práticas existentes ou opiniões de uma determinada população.

\subsection{População pesquisada e amostra da pesquisa}

Para Levin (1985) e Marconi e Lakatos (1996), a população a ser pesquisada, ou universo da pesquisa, é definida como o conjunto de indivíduos que partilham de, pelo menos, uma característica em comum. Com isso, o universo desta pesquisa é formado pelo conjunto das 50 empresas concessionárias de rodovias existentes no Brasil, cadastradas na Associação Brasileira de Concessionárias de Rodovia - ABCR, sendo que nove estão sediadas no estado do Rio Grande do Sul; uma, em Santa Catarina; sete, no Paraná; 21, em São Paulo; oito, no Rio de Janeiro; duas, em Minas Gerais; uma, no Espírito Santo; e uma, na Bahia. Foi realizada então uma amostragem de acordo com a adesão das empresas, alcançando 26 empresas de um total de 50 (52\%).

\subsection{Coleta de dados}

Segundo Beuren (2004), os instrumentos de pesquisa podem ser subdivididos por: observação, questionários, entrevistas, checklist e documentação. Para atender aos objetivos estabelecidos nesta pesquisa, optou-se pela utilização da metodologia de coleta de dados do 
tipo levantamento (survey). Foram enviados questionários aos responsáveis pelo orçamento das 50 empresas concessionárias de rodovias existentes atualmente no Brasil, objetivando uma amostragem por adesão, ou seja, de acordo com a quantidade de empresas que aderirem à pesquisa e responderem ao questionário.

Entre os meses de abril e maio de 2010, foram enviados por e-mail a carta de apresentação, o questionário composto por 26 questões subdivididas em dois blocos (informações específicas e gerais). Adicionalmente, foi realizado contato telefônico com as empresas objetivando explicar a finalidade da pesquisa e atingir um maior número de participantes.

\section{Apresentação e Análise dos Resultados}

Esse tópico tem como objetivo apresentar os resultados obtidos com a aplicação dos questionários que foram enviados às 50 concessionárias cadastradas na $\mathrm{ABCR}$, sendo que, destas, 26 responderam às questões. $\mathrm{O}$ questionário foi subdividido em dois blocos. $\mathrm{O}$ primeiro bloco objetiva identificar as informações gerais e evidenciar características das empresas e dos seus gestores; já o segundo bloco trata da análise das informações específicas e elucidará aspectos da gestão orçamentária das empresas pesquisadas.

Busca-se também apresentar possíveis comparações entre os achados desta pesquisa com estudos anteriores realizados acerca do tema.

\subsection{Apresentação e análise das informações gerais}

Das 26 empresas pesquisadas, $46 \%$ dos gestores respondentes são coordenadores, $31 \%$ são gerentes, $8 \%$ são controllers, $4 \%$ são analistas e outros $4 \%$ são diretores e ainda $8 \%$ exercem outra função (Gráfico 1).

\section{Gráfico 1 - Cargo do gestor respondente}

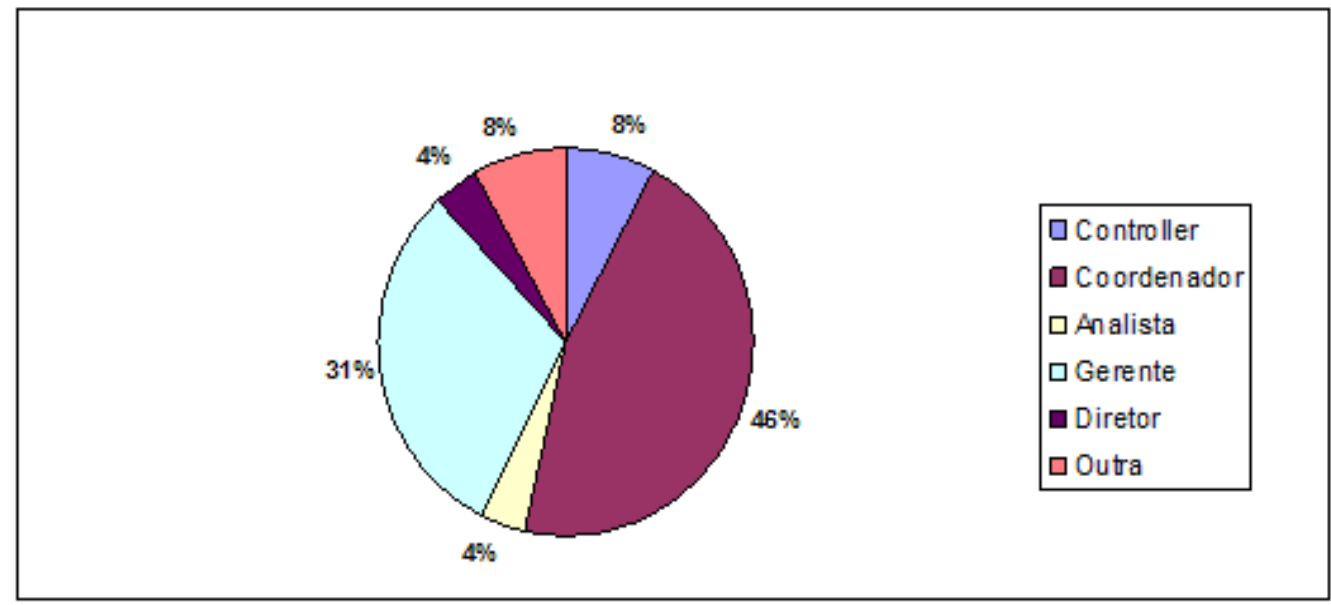

Fonte: Elaborado pelos autores.

Outro aspecto relevante a se destacar é com relação ao tempo de experiência dos gestores que responderam o questionário, de acordo com o exposto no Gráfico 2. Verificou-se que $77 \%$ dos gestores têm entre cinco e dez anos de experiência no setor em que atuam, 12\% 
tem entre três e cinco anos, $8 \%$ entre um e três anos e apenas $4 \%$ tem mais de dez anos de experiência.

Gráfico 2 - Tempo de experiência do gestor no setor em que atua

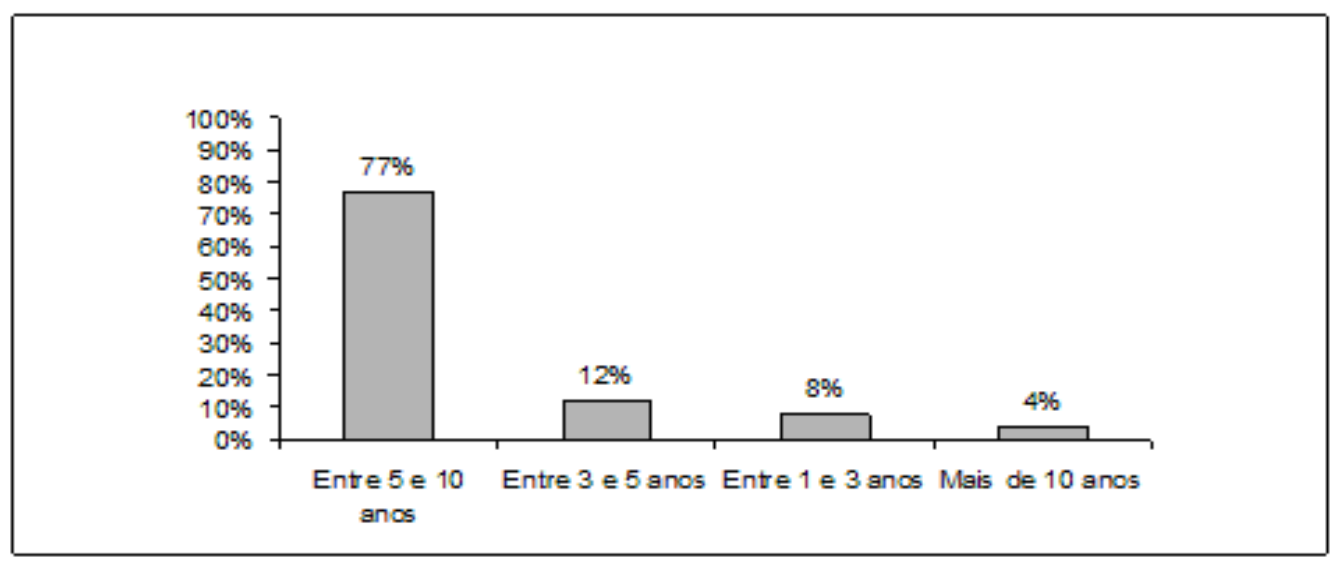

Fonte: Elaborado pelos autores.

Constatou-se também que $85 \%$ dos gestores desenvolvem suas atividades na empresa ou grupo empresarial atual há mais de cinco anos, $8 \%$ um ano ou menos e outros $8 \%$ entre um e cinco anos. Portanto, apresentam-se como profissionais que possuem vasto conhecimento sobre a empresa em que atuam.

Quanto à formação dos gestores, 57\% são pós-graduados em nível de especialização, $31 \%$ possuem MBA (Master of Business Administration), 9\% possuem superior completo e apenas $3 \%$ possuem pós-graduação no nível de mestrado, de acordo com exposto no Gráfico 3. Diante disso, observa-se que há indícios de esses profissionais possuírem formação condizente com sua ocupação.

\section{Gráfico 3 - Formação acadêmica dos gestores}

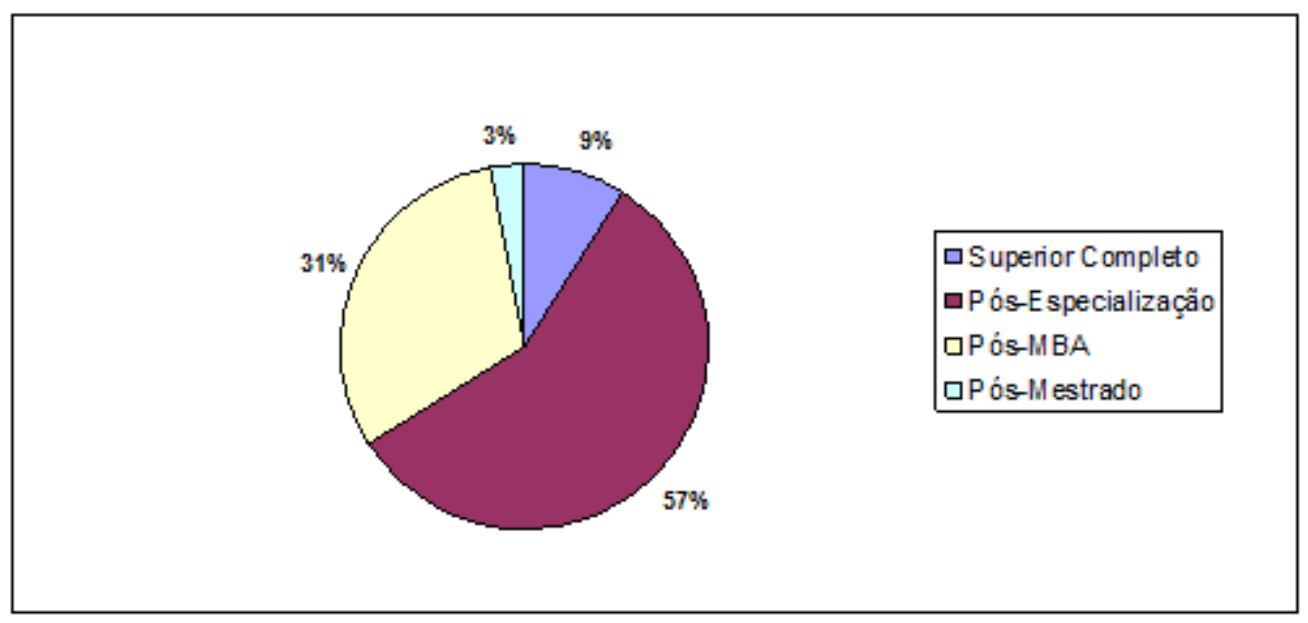

Fonte: Elaborado pelos autores.

Dos gestores respondentes, 37\% são formados em Ciências Contábeis, 37\% em Administração e $26 \%$ em Engenharia, conforme Gráfico 4. Como gestores responsáveis pelo 
orçamento nas organizações, observa-se formação compatível com as competências e habilidades requeridas nessa função.

\section{Gráfico 4 - Curso de formação dos gestores}

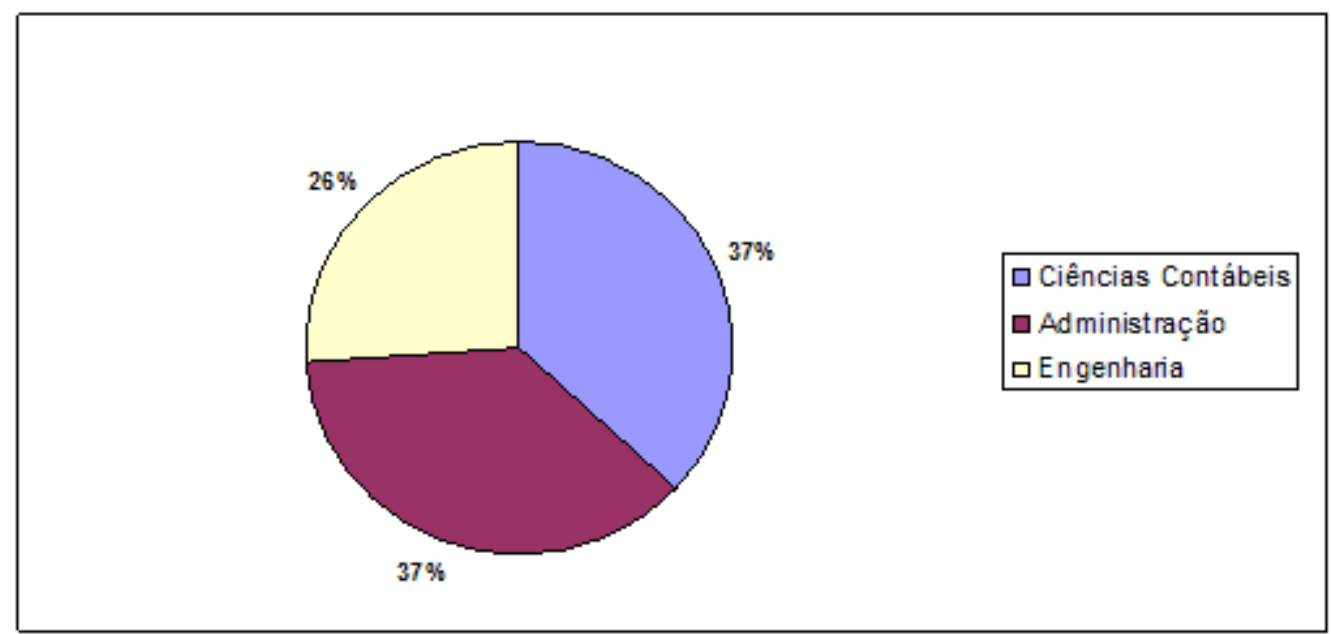

Fonte: Elaborado pelos autores.

Adicionalmente, com relação ao perfil do entrevistado, por meio do levantamento dos dados, constatou-se que $85 \%$ dos gestores são homens, e apenas $15 \%$ são mulheres e que entre eles $69 \%$ têm entre 36 e 40 anos, $19 \%$ tem entre 31 e 35 anos, e $12 \%$ tem entre 26 e 30 anos.

\subsection{Apresentação e análise das informações específicas}

Esse bloco é composto pela apresentação e análise de 15 questões de múltipla escolha, que visam identificar as características de gestão orçamentária das concessionárias de rodovia e três questões que tem como foco medir o grau de organização, controle e solidez das ferramentas orçamentárias existentes nas empresas.

Em primeiro lugar, ressalta-se o principal questionamento feito às concessionárias, o qual diz respeito às metodologias utilizadas para elaboração do orçamento. Verificou-se que entre as 26 empresas que responderam aos questionários, $73 \%$ utilizam como metodologia principal o Orçamento por Atividades, $8 \%$ o Orçamento Contínuo, outros $8 \%$ o Orçamento Base Zero e apenas $4 \%$ das empresas usam o Orçamento Perpétuo. Segue o Gráfico 5 que elucida tais informações.

Com a análise desses dados, nota-se que a maioria das empresas pesquisadas (73\%) opta por utilizar o orçamento por atividades como principal metodologia de gestão, fato que denota que grande parte das empresas participantes da pesquisa usa o ABC e projeta suas demonstrações em função dos direcionadores de custo empregados na atividade de concessão de rodovias. 
Gráfico 5 - Principais metodologias orçamentárias utilizadas pelas concessionárias

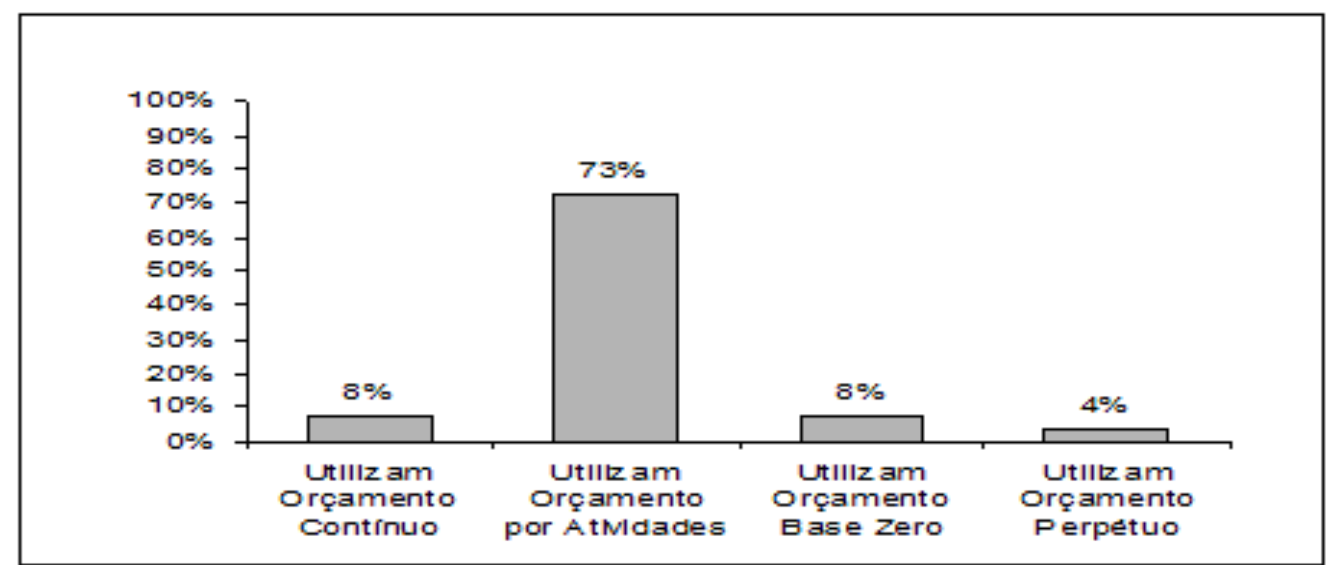

Fonte: Elaborado pelos autores.

Das 26 empresas que responderam ao questionário, todas dizem fazer projeção por cenários levando em consideração variáveis internas e externas. Outro fator de grande relevância questionado para as empresas foram os tipos de sistemas de gestão utilizados e se eles satisfaziam as expectativas e necessidades sobre os processos orçamentários.

Perguntados quanto à periodicidade de geração de dados contábeis confiáveis, $19 \%$ responderam que tais dados são emitidos mensalmente, $73 \%$ diariamente e $8 \%$ semanalmente. Evidencia-se que a confiabilidade nos dados emitidos, com periodicidade condizente para o seu acompanhamento, é relevante para uma gestão eficiente (Gráfico 6).

Gráfico 6 - Análise sobre o sistema de gestão de informações utilizado

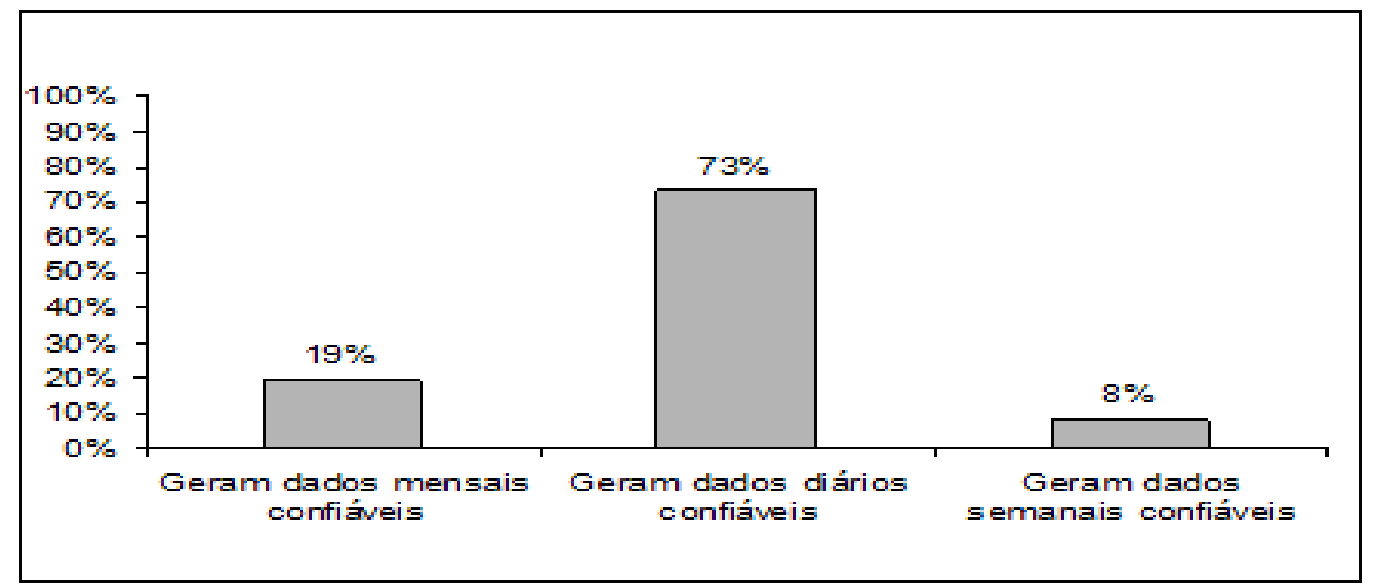

Fonte: Elaborado pelos autores.

Além disso, 35\% dos gestores orçamentários informaram utilizar o mesmo software contábil/financeiro para fazer a gestão orçamentária, pois atende às necessidades; $38 \%$ utilizam um software específico para gestão orçamentária; 8\% utilizam um software específico para gestão orçamentária mais um controle paralelo no software Excel e ainda 15\% fazem a gestão orçamentária exclusivamente no Excel.

Porém, ao serem questionados sobre a afirmativa a seguir: "O software utilizado fornece as informações e relatórios necessários para o gerenciamento orçamentária periódico 
da empresa (planejamento, execução e controle)?", $81 \%$ das empresas responderam que concordam totalmente com a afirmativa, $12 \%$ concordaram parcialmente, e apenas $8 \%$ não concordaram nem discordaram ou discordam parcialmente, elucidando com isso, a visão dos gestores de que os sistemas parecem ser eficientes.

Procurou-se também, identificar as relações existentes entre o departamento responsável pela gestão orçamentária e os demais setores da empresa. Primeiro, constatou-se que, em 54\% das empresas, o departamento de controladoria é o responsável por gerir o orçamento, em $31 \%$ o responsável é o setor administrativo/financeiro e em $12 \%$ os responsáveis são outros setores (planejamento e engenharia, por exemplo). Nota-se, portanto, que o departamento gestor, na maioria das vezes a controladoria, é responsável por administrar as reuniões para planejamento e controle orçamentário que ocorrem em todas as empresas pesquisadas e que em $96 \%$ destas tem periodicidade mensal e em apenas $4 \%$ a periodicidade é trimestral, conforme Gráfico 7.

\section{Gráfico 7 - Reuniões para acompanhamento e controle orçamentário}

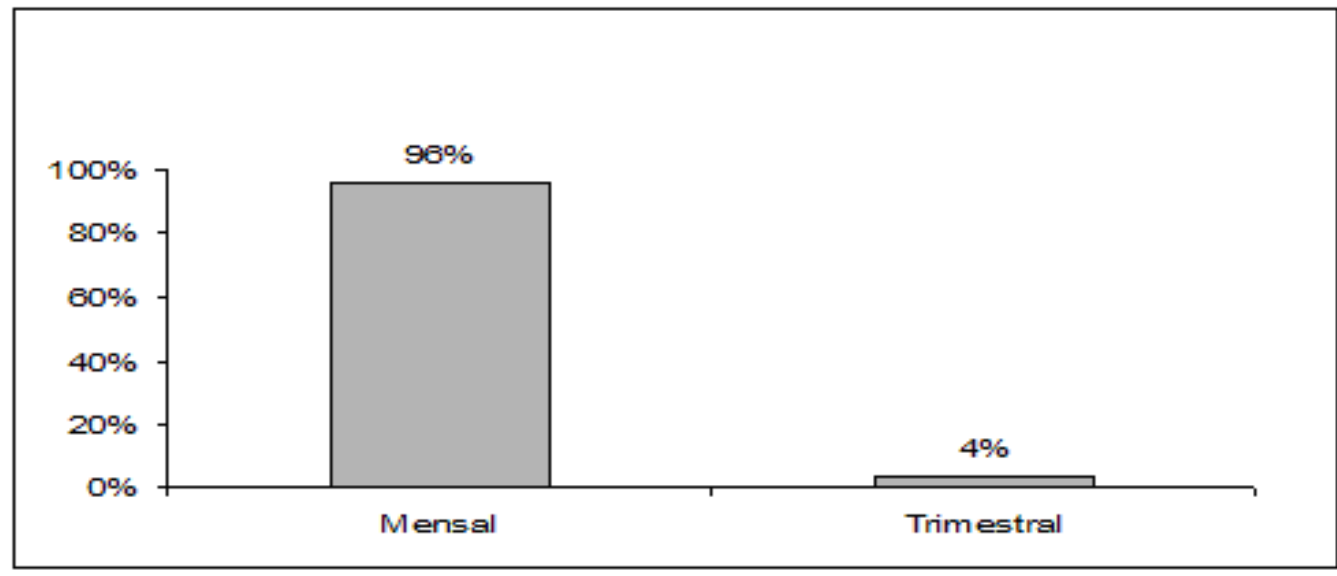

Fonte: Elaborado pelos autores.

Outro aspecto relevante que deve ser analisado no processo orçamentário é a periodicidade de revisão orçamentária, pois, no atual contexto organizacional, por mais adequada e eficiente que seja a metodologia orçamentária utilizada, sempre surgirão fatores (internos e externos) que poderão influenciar nas previsões e planos de ações futuras das organizações. Esse fato ratifica a preocupação com as revisões orçamentárias e qual é a periodicidade em que elas são realizadas.

Das empresas pesquisadas, $42 \%$ fazem revisão orçamentária anual, 38\% semestral, $12 \%$ trimestral, $4 \%$ fazem revisão mensal e os outros $4 \%$ não fazem revisão orçamentária. Essas informações elucidam que as revisões anuais e semestrais são as mais utilizadas pelas concessionárias e que poucas deixam de fazê-las, porém é importante ressaltar que as revisões anuais são menos eficientes, pois, como na maior parte os orçamentos são realizados para um período de doze meses, o nível de flexibilidade fica comprometido, já que os desvios ocorridos no decorrer dos meses não poderão ser ajustados para os meses seguintes. O Gráfico 8 expõe os percentuais apresentados anteriormente. 


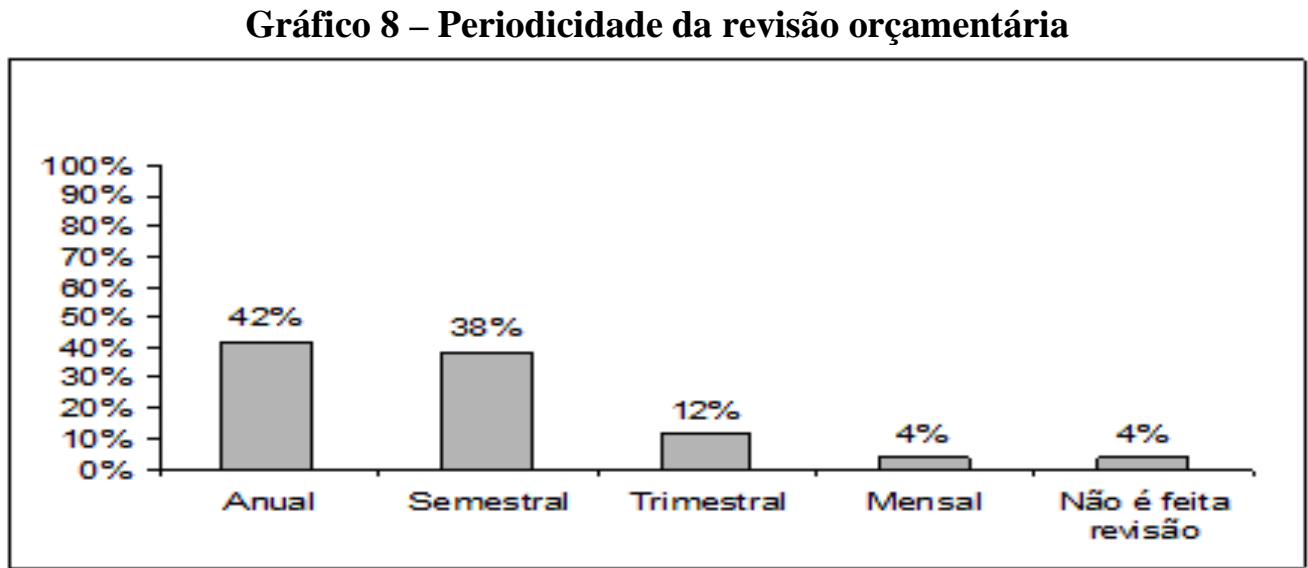

Fonte: Elaborado pelos autores.

Outro questionamento para os gestores orçamentários foi a respeito de qual é o percentual de tolerância de desvios com relação ao que foi orçado. Cerca de $90 \%$ dos respondentes afirmaram que não há percentual de tolerância e 12\% indicaram 5\% como sendo a tolerância entre realizado e orçado, não necessitando medidas corretivas imediatas a respeito (Gráfico 9).

Gráfico 9 - \% de tolerância de desvio com relação ao que foi orçado

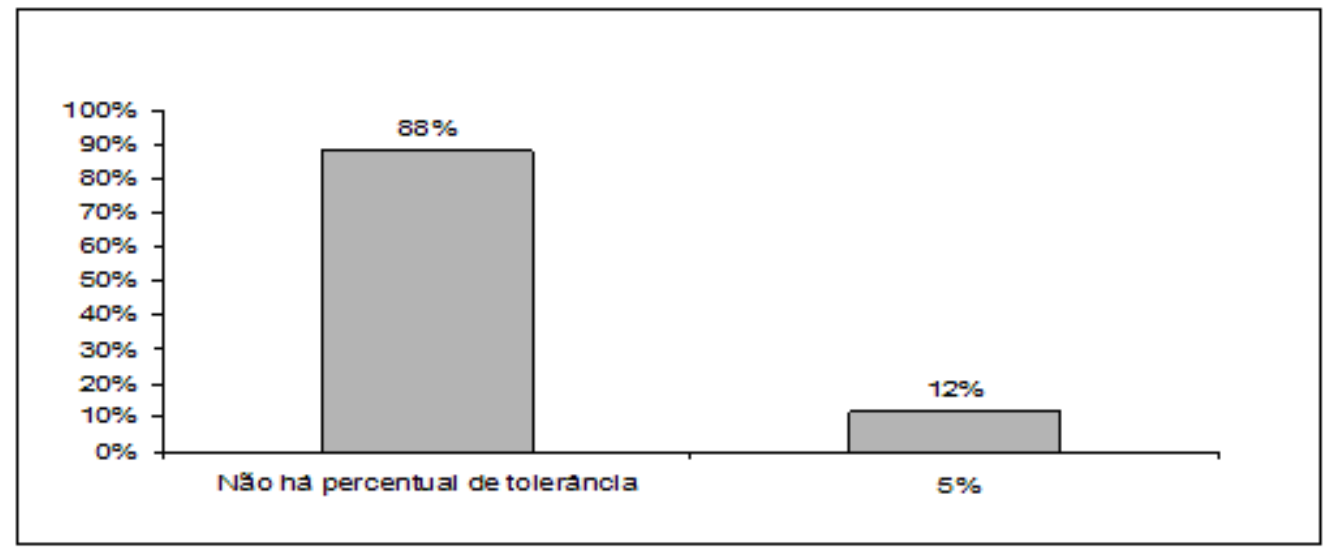

Fonte: Elaborado pelos autores.

A pesquisa em questão evidenciou as características do orçamento das empresas que aderiram à investigação. Tais características compõem o modelo orçamentário que pode refletir uma indicação do setor de atuação, inerente ao processo de planejamento e controle do orçamento de uma empresa concessionária de rodovias.

\section{Considerações Finais}

A partir do pressuposto de que o ramo de concessões rodoviárias está em fase de expansão, motivado por diversos fatores internos e externos relacionados à atual conjuntura socioeconômica e diretrizes políticas do País, buscou-se, por meio dessa investigação, 
identificar características dos processos relacionados ao planejamento, elaboração, controle e revisão do orçamento em cada empresa, objetivando a viabilização de melhorias.

Para tanto, considerou-se como questionamento para o desenvolvimento da presente pesquisa quais são as características da gestão orçamentária apresentadas em empresas do ramo de concessão rodoviária do Brasil. Aplicaram-se questionários aos gestores orçamentários das empresas, verificando como os conceitos e as metodologias orçamentárias são empregados empiricamente. Ressalta-se que dentre os 50 questionários enviados, 26 foram respondidos, ou seja, $52 \%$ do total.

A partir da análise das respostas obtidas, verificou-se que $73 \%$ das empresas utilizam como principal metodologia o orçamento por atividades, o que pode ser explicado pelo fato de que esta metodologia é uma extensão do Custeio Baseado em Atividades - ABC, que tem como foco a projeção dos recursos de acordo com as atividades e o uso de direcionadores para estimar e controlar os resultados, usando essas informações no planejamento e processo de avaliação.

O Activity Based Budgeting (ABB) - Orçamento Baseado em Atividades proporciona a eliminação de atividades supérfluas, redução do tempo ou dos recursos empenhados no cumprimento das atividades, seleção das atividades de custos mais baixos, possibilidade de definir prioridades mais coerentes de acordo com a realidade, oferecer justificativas de custo, maior monitoramento dos benefícios e avaliação do desempenho, objetivando constante melhoria. Ou seja, o planejamento, a execução e o monitoramento das atividades realizadas pelas concessionárias são possivelmente as informações mais importantes para o processo de tomada de desisões e acompanhamento dos recursos, uma vez que, nesse ramo, as empresas têm como principais objetivos a realização de diferentes e complexas obras de infraestrutura e o Orçamento por Atividades desempenha um papel essencial para o controle de recursos e cumprimento de metas estabelecidas nas atividades desenvolvidas nessas obras.

Fazendo referência aos estudos similares citados nesta pesquisa, percebeu-se que os procedimentos metodológicos utilizados não são idênticos, porém, são de mesma natureza, uma vez que este modelo de pesquisa, em sua maior parte, busca identificar, analisar e elucidar casos reais dentro de um contex to específico (ramo/segmento empresarial) de acordo com a vertente do objeto de pesquisa, fato que deixa explícita a possibilidade de comparação entre estes estudos, ainda que de maneira superficial, devido as especificidades de cada objetivo.

Em análise aos estudos similares realizados, chega-se aos principais achados de pesquisa acerca do objeto discutido.

Num primeiro estudo analisado, verificou-se que as empresas pesquisadas utilizavam o sistema orçamentário como principal mecanismo de controle gerencial e que não havia participação da média e baixa gerência no processo de planejamento.

Por sua vez, outra pesquisa identificou que o orçamento é uma das ferramentas de gestão que mais recebe críticas por parte dos pesquisadores nos últimos anos, porém, ainda é uma das mais citadas no meio acadêmico em nível de importância para auxiliar as funções administrativas de planejamento e controle e que dentre estas críticas, as que mais de destacaram são as que mencionam que o orçamento tem foco na redução de custo e não na criação de valor e aquelas que dizem que a revisão do orçamento é lenta e a instituição não o gerencia de forma rápida.

Já um novo estudo analisado discute o papel do orçamento nas organizações ao abordar problemas costumeiramente existentes no ambiente de gestão e depois investiga o desenvolvimento e utilização do orçamento numa amostra piloto de 28 indústrias. Após 
análise dos dados levantados, evidenciou-se que maior parte dos gestores conhecem o orçamento, porém não o utilizam. Em conclusão notou-se que a adoção do orçamento empresarial e suas variáveis de controle estão evoluindo nas empresas da amostra.

A derradeira pesquisa estudada evidenciou que os fatores contingenciais relacionados ao ambiente, tecnologia e, principalmente, ao porte da empresa influenciaram as inovações nos atributos do sistema orçamentários da organização.

Com base nos achados de pesquisas citados e em análise aos resultados apresentados nesta pesquisa, torna-se possível e conveniente expor as peculiaridades aqui aclaradas, uma vez que a gestão orçamentária é tema relevante e essencial de discussão em meio aos acadêmicos e profissionais distribuídos ao redor do mundo.

Em primeiro lugar, faz-se necessário elucidar que em todas as pesquisas observadas, assim como nesta presente, evidenciou-se a importância do orçamento em uma organização, seja para contribuir com informações de qualidade e assim aumentar a eficiência e eficácia dos processos e resultados envolvidos, seja para limitar o desenvolvimento organizacional, quando utilizado de maneira inadequada e/ou ineficiente.

Outro fator relevante que se verifica é a necessidade de estudos específicos para cada ramo/segmento empresarial, já que peculiaridades existem, principalmente no que se refere a fatores contingenciais, relacionados ao ambiente, tecnologia disponível e tamanho das organizações, o que leva ao consenso de que cada estudo aqui citado inda mais o presente, devem ser analisados distintamente em sua essência, uma vez que tratam do mesmo objeto, o orçamento, porém sob formas, circunstancias, necessidades, dificuldades e principalmente prioridades diferenciadas, porém, as diretrizes básicas e essenciais da gestão orçamentária devem predominar e se adaptar ao método orçamentário mais adequado as particularidades de cada segmento.

Por fim, torna-se clara a relevância e contribuição que cada estudo realizado, sobre determinado tema, agrega ao desenvolvimento organizacional, acadêmico e social, uma vez que podem servir como base aos gestores responsáveis pelas tomadas de decisões, podendo com isso, contribuir para o alcance dos objetivos estipulados, seja qual for o segmento empresarial que a entidade atue.

À luz dessas considerações, nota-se que foram identificadas as principais características da gestão orçamentária de empresas do ramo de concessão rodoviária do Brasil, possibilitando assim um entendimento mais eficiente acerca dos processos de gestão desse ramo de atividades que se torna, a cada dia, mais fundamental para o desenvolvimento da sociedade e economia brasileira. Recomenda-se que este estudo seja utilizado no auxílio das atividades rotineiras desenvolvidas pelas organizações em que está se focando e que a partir dos resultados aqui explicitados sejam realizados novos estudos sobre esse segmento organizacional, com o objetivo de detalhar e aperfeiçoar os processos de gestão necessários para a manutenção e desenvolvimento dessas organizações no tangente à controladoria.

\section{Referências}

ASSOCIAÇÃO BRASILEIRA DE CONCESSIONÁRIA DE RODOVIAS - ABCR. Concessionárias Cadastradas. 2010. São Paulo. Disponível em:<http://www.abcr.org.br/concessoes>. Acesso em 25/02/2010. 
ALVES, A. J. O planejamento de pesquisas qualitativas em educação. Cadernos de Pesquisa, São Paulo, v. 77, p. 53-61, maio, 1991.

BEUREN, I. M. et al. Como elaborar trabalhos monográficos em contabilidade: teoria e prática. 2. ed. São Paulo: Atlas, 2004.

BOISVERT, Hugues. Contabilidade Baseada em atividades e controle de Gestão. Québec, 1999.

BRASIL. Lei n. 8.987 de 13 de fevereiro de 1995. Dispõe sobre o regime de concessão e permissão da prestação de serviços públicos previsto no art. 175 da Constituição Federal, e dá outras providências. Disponível em:<www.planalto.gov.br/ccivil/LEIS/L8987 > acessado em 20/04/2010.

BRIMSON, J.A. Contabilidade por atividades. São Paulo: Ed. Atlas, 1996.

BROOKSON, Stephen, Como elaborar orçamentos. São Paulo: Publifolha, 2000.

CERVO, A. L.; BERVIAN, P. A. Metodologia Científica. 5. Edição. São Paulo: Ed. Prentice Hall, 2002.

COSTA, A. M.; MORITZ, G. O.; MACHADO, F. M. V. Contribuições do Orçamento Base Zero (OBZ) no planejamento e controle de resultados em organizações empresariais. Revista Contemporânea de Contabilidade. v. 4, n. 8, 2007.

ESPEJO, M. B. Perfil dos atributos do sistema orçamentário sob a perspectiva contingencial: Uma abordagem Multivariada. 216 f. (Doutorado em Contabilidade) Faculdade de Economia, Administração e Contabilidade, Universidade de São Paulo, São Paulo, 1998.

FANK, O. L.; ANGONESE, R.; LAVARDA, C. E. F. Apercepção dos gestores acadêmicos de uma IES quanto às críticas ao orçamento. Revista Contabilidade, Gestão e Governança, v. $14 \cdot$ n. $1 \cdot$ p. 82-93, jan./abr. 2011.

FERREIRA. S. de A. Direito administrativo didático. 3. ed. Rio de Janeiro: Forense, 1985.

FREZATTI, F. Orçamento Empresarial: Planejamento e Controle Gerencial. São Paulo: Atlas, 2006.

GIL, A. C. Como elaborar projetos de pesquisa. São Paulo: Atlas, 1991.

GOLDENBERG, M. A arte de pesquisar: como fazer pesquisa qualitativa em Ciências Sociais. Rio de Janeiro: Record, 1999.

HANSEN, S. C.; OTLEY, D.; VAN DER STEDE, W. A. Practice developments in budgeting: an overview and research perspective. Journal of Management Accounting Research, v. 15, p. 95- 116, 2003.

HOPE, J. ; FRASER, R. Beyond Budgeting: how manager can break free from the annual performance trap. Boston, EUA: Harvard Business School Press, 2003.

HORNGREN, C. T. Contabilidade de Custos. 9. ed. Rio de Janeiro: LTC, 2000.

HORNGREN, C. T. Introdução à contabilidade gerencial. 5. ed., Rio de Janeiro: Prentice Hall do Brasil, 1985. 
JONES, R. L; TRENTIN, H. G. Orçamento - a chave do planejamento e controle. São Paulo: MC Graw Hil, 1978.

LUNKES. R. J. Manual de orçamento. São Paulo: Atlas, 2003.

MARCONI, M. D. A.; LAKATOS, E. M. Técnicas de pesquisa: planejamento e execução de pesquisas, amostragens e técnicas de pesquisas, elaboração, análise e interpretação de dados. 3. ed. São Paulo: Atlas, 1996.

MEDAUAR, O. Poder de Polícia. A Força Policial. São Paulo, n. 6, p. 51-61, abr./jun. 1995.

MEIRELLES. H. L. Direito administrativo brasileiro. 27. ed. São Paulo: Malheiros. 2003.

NEVES, J. L. Pesquisa qualitativa: características, usos e possibilidades. Cadernos de Pesquisas em Administração, v. 1, n. 3, 2º sem., 1996.

PADOVEZE, C. L. Controladoria Estratégica e Operacional. 2. ed. São Paulo: Cengage, 2009.

PANUCCI FILHO, L.; ESPEJO, M. M.S.; NASCIMENTO, C.; CLEMENTE, A. O orçamento empresarial na atualidade: um estudo piloto. $9 \mathrm{f}$. (Publicação permanente da Revista ADMpg-UEPG) Universidade Federal do Paraná-UFPR, Brasil, 2010.

PATTON, M. Qualitative research and evaluation methods. Londres, Thousand Oaks : Sage Publications, 2002.

PHYRR, PETER A. "Orçamento Base Zero" - Um instrumento administrativo prático para avaliação das despesas, São Paulo: Interciência, 1981

RICHARDSON, R. J. et al. Pesquisa Social: métodos e técnicas. 3. ed. revista e ampliada. São Paulo: Atlas, 2008.

SCHUBERT, P. Orçamento empresarial integrado. Rio de Janeiro: LTC, 1985.

SANTOS, J. A., PARRA FILHO, D. Metodologia científica. São Paulo: Futura, 1998.

SILVA, A. C., GONÇALVES, R. C. M. G. Caracterização do uso de sistemas de controle orçamentário: um estudo multi-caso . In: $6^{\circ}$ Congresso USP de Controladoria e Contabilidade, 2006, São Paulo. Anais... São Paulo: Congresso USP de Controladoria e Contabilidade, 2006.

SILVA, A. C., GONÇALVES, R. C. M. G. Aplicação da abordagem contingencial na caracterização do uso do sistema de controle orçamentário: um estudo multicaso. JISTEM J.Inf.Syst. Technol. Manag. 2008, vol.5, no.1, p.163-184

SOUTO, M. J. V. Desestatização: privatização, concessões, terceirizações e regulação. 4. ed. Rio de janeiro: Editora Lumen Juris, 2001.

TAYLOR, F. W. (1978) Princípios da Administração Científica. São Paulo: Atlas

VAENA, Maurício, HUETZ, Leopoldo V. Orçamento Empresarial e seu controle. São Paulo: Atlas, 1961.

VERHAGEM, J. A.; LAVARDA, C. E. F. Inovações no processo orçamentário a luz da abordagem contingencial: o caso de uma empresa de grande porte do sul do brasil. $16 \mathrm{f}$. (Artigo apresentado no Congresso ANPCONT-2010) FURB - Universidade Regional de Blumenau, Brasil, 2010. 
WELSCH, G. A. Orçamento empresarial. 3. ed. São Paulo: Atlas, 1983. 